\title{
Active repression of RAR signaling is required for head formation
}

\author{
Tetsuya Koide, ${ }^{1,2}$ Michael Downes, ${ }^{3}$ Roshantha A.S. Chandraratna, ${ }^{4}$ Bruce Blumberg, ${ }^{2,5}$ \\ and Kazuhiko Umesono ${ }^{1,6}$ \\ ${ }^{1}$ Graduate School of Biostudies, Kyoto University, Sakyoku, Kyoto 606-8507, Japan; ${ }^{2}$ Department of Developmental and Cell \\ Biology, University of California, Irvine, California 92697, USA; ${ }^{3}$ Gene Expression Laboratory, The Salk Institute for \\ Biological Studies, La Jolla, California 92037, USA; ${ }^{4}$ Retinoid Research, Departments of Chemistry and Biology, Allergan \\ Inc., Irvine, California 92612, USA
}

The retinoic acid receptors (RARs) recruit coactivator and corepressor proteins to activate or repress the transcription of target genes depending on the presence of retinoic acid (RA). Despite a detailed molecular understanding of how corepressor complexes function, there is no in vivo evidence to support a necessary function for RAR-mediated repression. Signaling through RARs is required for patterning along the anteroposterior (A-P) axis, particularly in the hindbrain and posterior, although the absence of RA is required for correct anterior patterning. Because RARs and corepressors are present in regions in which RA is absent, we hypothesized that repression mediated through unliganded RARs might be important for anterior patterning. To test this hypothesis, specific reagents were used that either reduce or augment RAR-mediated repression. Derepression of RAR signaling by expressing a dominant-negative corepressor resulted in embryos that exhibited phenotypes similar to those treated by RA. Anterior structures such as forebrain and cement gland were greatly reduced, as was the expression of molecular markers. Enhancement of target gene repression using an RAR inverse agonist resulted in up-regulation of anterior neural markers and expansion of anterior structures. Morpholino antisense oligonucleotide-mediated RAR $\alpha$ loss-of-function phenocopied the effects of RA treatment and dominant-negative corepressor expression. Microinjection of wild-type or dominant-negative $R A R \alpha$ rescued the morpholino phenotype, confirming that RAR is functioning anteriorly as a transcriptional repressor. Lastly, increasing RAR-mediated repression potentiated head-inducing activity of the growth factor inhibitor cerberus, whereas releasing RAR-mediated repression blocked cerberus from inducing ectopic heads. We conclude that RAR-mediated repression of target genes is critical for head formation. This requirement establishes an important biological role for active repression of target genes by nuclear hormone receptors and illustrates a novel function for RARs during vertebrate development.

[Key Words: RAR; corepressor; repression; anteroposterior patterning]

Received May 1, 2001; revised version accepted June 22, 2001.

Retinoids regulate many aspects of vertebrate development and organogenesis, primarily through the actions of two classes of ligand-activated transcription factors, the RARs and RXRs. RARs are activated by all-trans and 9-cis retinoic acid (RA), whereas RXRs are activated by 9-cis retinoic acid (Blumberg 1997) as well as a small number of other nonretinoid compounds (Kitareewan et al. 1996; de Urquiza et al. 2000). RARs function as obligatory heterodimers with RXR, whereas RXRs can also function as homodimers (Mangelsdorf and Evans 1995). The biosynthesis of RA is largely under the control of retinaldehyde dehydrogenase 2 , whereas the majority of retinoic acid clearance is thought to be mediated

${ }^{5}$ Corresponding author.

E-MAIL blumberg@uci.edu; FAX (949) 824-4709.

${ }^{6}$ Deceased April 12, 1999.

Article and publication are at http://www.genesdev.org/cgi/doi/10.1101/ gad.908801. by CYP26 (Maden 1999; Swindell et al. 1999). Transcriptional activation by retinoid receptors is thus dependent on the presence of the receptors, the ligands, and transcriptional coregulators (Minucci and Pelicci 1999).

RARs, like many other nuclear receptors, recruit different sets of cofactors depending on whether or not ligand is bound to the receptor. The receptor binds to DNA and, in the presence of ligand, recruits a coactivator complex that acetylates histones and activates transcription. The role of RAR as a transcriptional activator is well documented from loss-of-function analyses and it is known to be essential for numerous processes during development (Mark et al. 1999). In the absence of ligand, RARs bind to DNA and interact with corepressors such as SMRT (silencing mediator of retinoic acid receptor and thyroid hormone receptor) (Chen et al. 1996) and N-CoR (nuclear receptor corepressor) (Horlein et al. 1995). Both corepressors recruit Sin 3 and histone 
deacetylases (HDACs), thus forming multisubunit repressor complexes that deacetylate histones, leading to chromatin condensation and transcriptional repression (for review, see Glass and Rosenfeld 2000; Hu and Lazar 2000). It is well known that transcriptional repression plays many important roles in development (Mannervik et al. 1999|. Targeted disruption of N-CoR confirms the involvement of corepressor proteins in erythrocyte, thymocyte, and CNS development (Jepsen et al. 2000). However, until now there has been no evidence to support an essential normal biological role for the repression mediated by unliganded nuclear receptors.

Secreted factors released from the organizer and its derivatives regulate neural induction and anteroposterior $(\mathrm{A}-\mathrm{P})$ patterning of the neuroectoderm during early amphibian development (for review, see Sasai and De Robertis 1997). Vertebrate neural induction and A-P patterning begin during gastrulation and continue throughout neurulation. We and others showed that signaling through retinoid receptors is required for the formation of primary neurons (Blumberg et al. 1997; Sharpe and Goldstone 1997, 2000) and correct A-P patterning of the CNS (Blumberg et al. 1997; Kolm et al. 1997; van der Wees et al. 1998). Up-regulation of retinoid signaling by treating early embryos with exogenous RA or microinjecting constitutively active RARs can convert anterior neural tissue to posterior values at low levels while leading to anterior truncations at high levels (for review, see Blumberg 1997). Taken together, these data support the identification of retinoid signaling as an essential component of the activity required to posteriorize the embryonic A-P axis.

A variety of endogenous bioactive retinoids exist in embryos (Durston et al. 1989; Pijnappel et al. 1993, 1998; Blumberg et al. 1996) although their spatial distributions are not well characterized. Two critical enzymes regulate the availability of RA and consequently its role in A-P patterning. RALDH-2 converts retinaldehyde to RA and is thought to be the primary source of RA during development. In contrast, CYP26 converts RA to 4-OH RA and is thought to mediate the breakdown and clearance of retinoic acid (White et al. 1996; Maden 1999). However, it is interesting to note that 4-OH and 4-oxo RAs are as active as RA in embryos (Pijnappel et al. 1993, 1998), whereas 4-OH and 4-oxo retinol and retinaldehyde are more biologically active than retinol or retinaldehyde (Achkar et al. 1996; Blumberg et al. 1996). RALDH-2 is expressed predominantly in the posterior mesoderm with a sharp anterior border in the gastrula at what will become the level of the first somite (Chen et al. 2001). CYP26 is expressed in the prospective anterior neural plate as well as the underlying prechordal mesoderm at gastrula (Hollemann et al. 1998; de Roos et al. 1999). Neither enzyme is expressed in the region that will become the hindbrain (Maden 1999; Chen et al. 2001). Mice deficient in RALDH-2 expression exhibit severe posterior axial defects but no obvious effect on anterior CNS (Niederreither et al. 1999). Experiments with retinoid-responsive reporter mice show that RAR signaling is absent in anterior neural tissue during gastrulation
(Rossant et al. 1991), although RARs are present. These studies suggest that transcriptional activation through RARs is not required at the anterior part of the embryo (Maden 1999; Chen et al. 2001). Down-regulation of RA synthesis by misexpressing CYP26 in Xenopus embryos expands the expression domain of anterior neural markers (Hollemann et al. 1998), whereas mice deficient in CYP26 exhibit defects in anterior neural patterning (Abu-Abed et al. 2001). The available evidence therefore suggests that the absence of retinoid signaling is required for anterior patterning.

RAR $\alpha$ and RAR $\gamma$ are both expressed in prospective anterior tissues during Xenopus development at the time when embryos are sensitive to treatment with exogenous retinoids (Ellinger-Ziegelbauer and Dreyer 1991, 1993; Sharpe 1992; Pfeffer and De Robertis 1994). We hypothesized that repression mediated by unliganded receptors might play an important role in anterior patterning and investigated the effects of modulating this repression on early development. Derepression of RAR signaling was achieved by microinjecting a dominantnegative corepressor into Xenopus embryos. The resulting embryos exhibited phenotypes similar to those treated with RA in that anterior structures such as forebrain and cement gland were greatly reduced. Morpholino antisense oligonucleotides were used to investigate the effect of RAR $\alpha$ loss-of-function. Injected embryos showed a posteriorized phenotype very similar to those treated with RA or microinjected with the dominantnegative corepressor. The morpholino phenotype could be rescued by wild-type $\mathrm{RAR} \alpha$ or its dominant-negative variant, confirming that it is repression by RARs that is critical for head formation. Enhancement of target gene repression by use of an RAR inverse agonist (AGN193109) expanded head structures and up-regulated anterior neural markers. We conclude that RARmediated repression of target genes is critical for the establishment of head structures. This requirement establishes an important biological role for nuclear receptor-mediated repression of target genes and illustrates a novel function for RARs during vertebrate development.

\section{Results}

Developmental expression of corepressors and $x R A R \alpha$

Corepressor proteins such as SMRT (Chen et al. 1996) and N-CoR (Horlein et al. 1995) repress transcription by interacting with nuclear receptors and other DNA-binding proteins and recruiting a complex containing histone deacetylase (HDAC) activity to the target promoters (Minucci and Pelicci 1999). We used human SMRT to screen for Xenopus homologs and identified 12 related cDNAs. DNA sequence analysis revealed that 11 cDNAs encode SMRT and 1 cDNA encodes N-CoR (data not shown). Whole-mount in situ hybridization and RT-PCR were used to evaluate the temporal and spatial expression of Xenopus corepressor mRNAs (Fig. 1). Both mRNAs are expressed in the unfertilized egg and persist at relatively constant levels throughout early embryogenesis (Fig. 

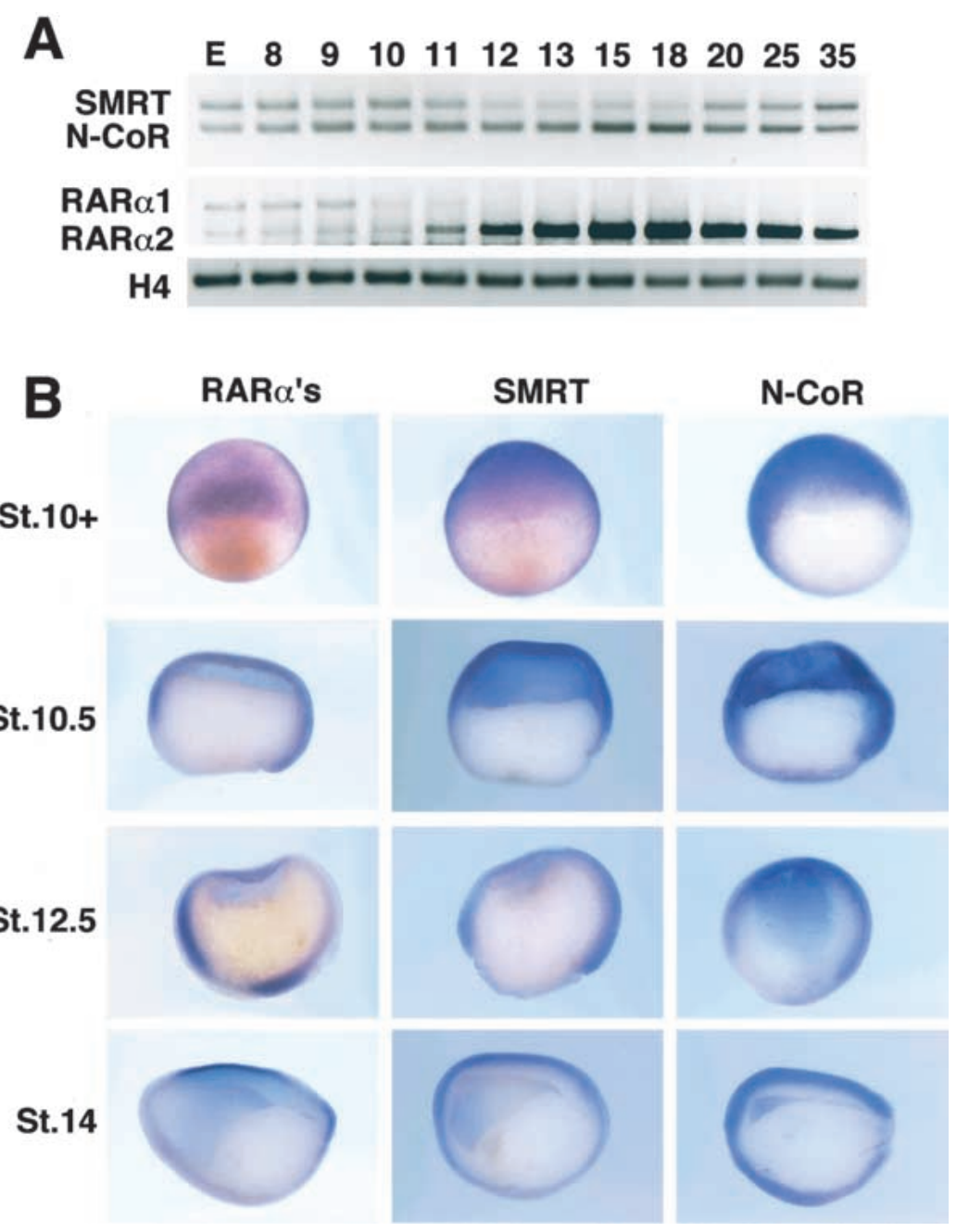

Figure 1. Developmental expression of corepressors and xRAR $\alpha$ s. (A) RT-PCR analysis during development (stages indicated above the lanes) shows maternal and zygotic transcription of $x S M R T, x N-C o R, x R A R \alpha 1$, and $x R A R \alpha 2$ compared with histone $\mathrm{H} 4$ control. (B) Whole-mount in situ hybridization analysis of xRAR $\alpha$, xSMRT, and xN-CoR transcripts. (St. 10+) Dorsal view of early gastrula embryos. xRAR $\alpha$ s and both corepressors are expressed in the ectoderm and dorsal blastopore lip. (St. 10.5, St. 12.5) Embryos were cut sagittally and oriented with the animal side up and dorsal lip to the right. $x R A R \alpha s, x S M R T$, and $x N-C o R$ are expressed in the ectoderm, dorsal and ventral mesoderm. (St. 14) Dorsal side is up, anterior side is left. XSMRT and $\mathrm{xN}-\mathrm{CoR}$ are expressed in the anterior neuroectoderm, but xRAR $\alpha$ s are not expressed in this region.
1A). Both SMRT and N-CoR are widely distributed in the early embryo, particularly the ectoderm with lower levels in the dorsal and ventral mesoderm (Fig. 1B). SMRT and $\mathrm{N}-\mathrm{CoR}$ mRNAs are expressed in the developing CNS of neurula stage embryos (Fig. 1B).

Two major isoforms of $\operatorname{RAR} \alpha$ are expressed during early development, $x \operatorname{RAR} \alpha 1$ and $x R A R \alpha 2$ (Fig. 1; Sharpe 1992). Both isoforms are expressed in the egg and persist throughout early cleavage. After gastrulation, the $x R A R \alpha 2$ mRNA increases in abundance, whereas $\mathrm{xRAR} \alpha 1$ becomes undetectable (Fig. 1A) (Blumberg et al. 1992). No difference in the expression of the two isoforms could be detected by whole-mount in situ hybridization (data not shown). xRAR $\alpha 2$ mRNAs are detectable throughout the ectoderm with higher levels in the dorsal and ventral marginal zones (Fig. 1B). It is notable that RAR $\alpha$ and corepressor mRNAs show concordant temporal and spatial expression, particularly during the early gastrula stages that are most sensitive to RA signaling.

\section{Inhibition of RAR-mediated repression by $c-S M R T$}

Corepressors contain multiple, separable functional domains. These include repressor domains in the amino terminus of the protein and receptor-interaction domains in the carboxy-terminal part of the protein (for reviews, see Xu et al. 1999; Hu and Lazar 2000; Privalsky 2001). Corepressor fragments containing only the receptor-interacting domains would be expected to compete with endogenous corepressors for receptor binding, preventing recruitment of HDACs and thereby relieving repression. Chen and colleagues showed that the carboxyterminal portion of SMRT, termed c-SMRT, which contains the receptor-interacting domains (but not the repression domains) could effectively release the repression effect in mammalian cells without affecting activation (Chen et al. 1996). Thus, c-SMRT is a dominantnegative corepressor.

To establish that c-SMRT functions as a dominantnegative corepressor in vivo, we tested its ability to block repression mediated by unliganded Xenopus $\mathrm{RAR} \alpha$. GAL-xRAR $\alpha$ mRNA was microinjected into Xenopus embryos together with a GAL4-dependent luciferase reporter in the presence or absence of coinjected c-SMRT mRNA. GAL-xRAR $\alpha$ can strongly repress the basal promoter activity (Fig. 2) presumably by interacting with endogenous corepressor proteins. Coinjection of c-SMRT mRNA completely relieved GAL-xRAR $\alpha$-medi- 

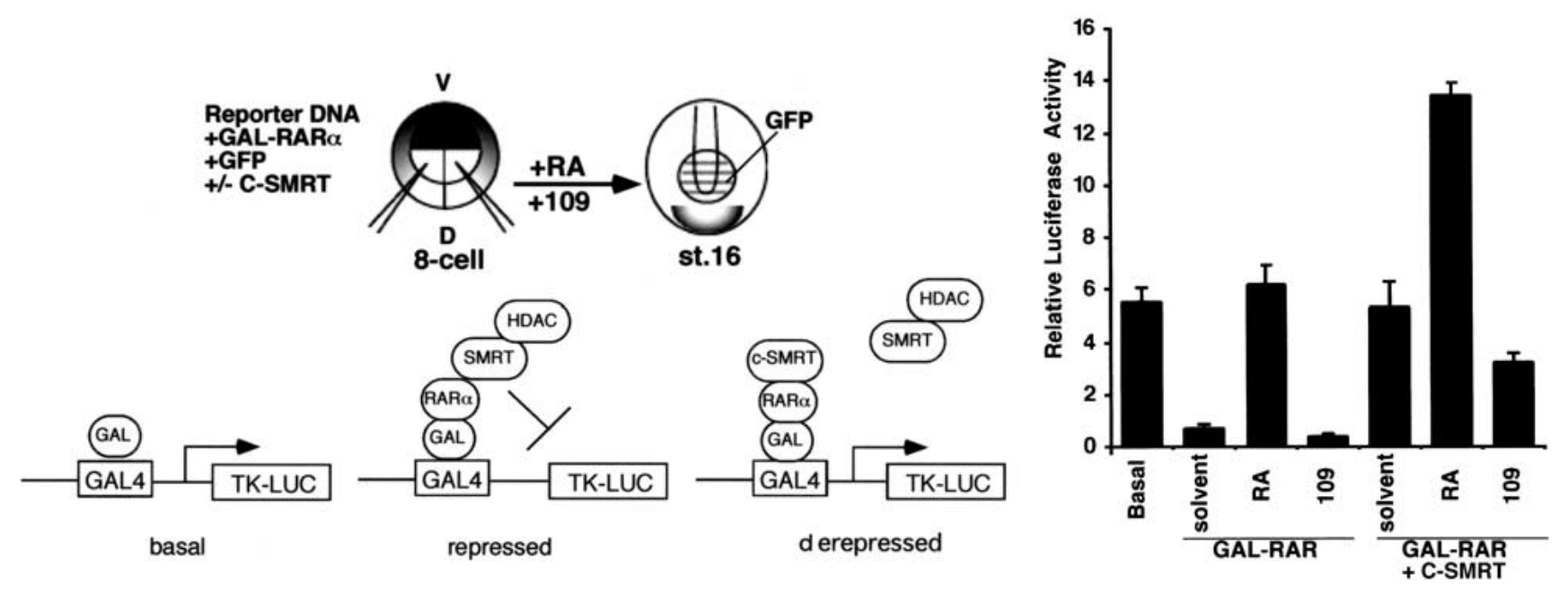

Figure 2. Transcriptional repression by RAR $\alpha$ in Xenopus embryos. Gal4 ${ }_{\text {UAS }}$ reporter plasmid was injected either alone (left), together with mRNA encoding Gal4-xRAR $\alpha(200 \mathrm{pg}$ ) (middle, GAL-RAR), or together with Gal4-xRAR $\alpha(200 \mathrm{pg})$ and c-SMRT (4 ng) mRNAs (right, GAL-RAR+C-SMRT) into both dorsal blastomeres at the 8-cell stage. Embryos were collected at stage 16 and luciferase assays performed. Similar results were obtained from three independent experiments.

ated repression (Fig. 2), showing that c-SMRT acts in a dominant-negative manner to relieve repression by endogenous corepressors. The overall level of RA-induced reporter gene activity was about twice as high in the presence of c-SMRT (Fig. 2), suggesting that there are considerable amounts of endogenous corepressor proteins in the early embryo. As shown in Figure 1, SMRT and N-CoR are expressed abundantly in the gastrula animal cap and later expressed in the neural plate and head. Treatment of the embryos with a receptor antagonist AGN193109 that stabilizes the interaction between RARs and corepressors enhances RAR-mediated repression (Fig. 2). AGN193109 also reduces c-SMRT-mediated derepression of GAL-xRAR $\alpha$ (Fig. 2). This is intriguing as one might expect that AGN193109 would stabilize the c-SMRT-RAR complex, leading to enhancement of derepression. One possible explanation for this result is that the full-length corepressors have a greater affinity for RAR than does c-SMRT.

\section{Eliminating RAR-mediated repression abolishes head formation}

We have shown previously that suppression of RAR signaling by microinjecting mRNA encoding a dominantnegative $\mathrm{xRAR} \alpha$ enhanced the expression of anterior markers (Blumberg et al. 1997). Other studies have shown that the absence of retinoid signaling was required for normal anterior development (Hollemann et al. 1998; de Roos et al. 1999; Abu-Abed et al. 2001; Sakai et al. 2001). We hypothesized that active repression by unliganded RARs, rather than the mere absence of retinoid signaling, is important for anterior patterning, and to test this, we took two complementary approaches to block RAR repression.
The developmental effects of uncoupling RAR-mediated repression from activation was tested by use of microinjection of c-SMRT mRNA. Microinjected embryos were allowed to develop until the tadpole stage, then fixed and scored for the degree of anterior development. Microinjection of c-SMRT gave rise to posteriorized embryos $(54 \%, n=180)$ (Fig. 3b). Anterior structures such as cement gland and eyes were greatly reduced or absent and the embryos were shorter (Fig. 3, cf. a and b with c), although the tails appeared largely unaffected. Remarkably, the most severely affected c-SMRT-injected embryos (Fig. 3b) exhibited effects similar to those elicited by treatment with RA (Fig. 3a). We conclude that relief of RAR-mediated repression by c-SMRT is sufficient to posteriorize the embryonic A/P axis.

Because interference with SMRT-mediated repression might affect pathways other than RAR (e.g., thyroid hormone, Notch), another approach was taken to confirm the involvement of xRAR $\alpha$ in the phenotype elicited by c-SMRT injection. We microinjected an antisense morpholino oligonucleotide (Summerton 1999; Ekker 2000; Heasman et al. 2000) that inhibits translation from endogenous RAR $\alpha$ mRNAs. Embryos injected with a morpholino directed against RAR $\alpha 1$ (Fig. 3d), RAR $\alpha 2$ (Fig. 3e), or a mixture of both oligos (Fig. 3f) showed phenotypes essentially indistinguishable from those injected with c-SMRT (Fig. 3b) or treated with RA (Fig. 3a). A control morpholino oligo had no effect (Fig. 3c). The mixed morpholino consistently gave the strongest phenotype, followed by the xRAR $\alpha 2$ and then the xRAR $\alpha 1$ morpholinos. Microinjection of xRAR $\alpha 1$ (not shown) or xRAR $\alpha 2$ mRNA (Fig. $3 \mathrm{~g}$ ) rescued the effects of the morpholino oligo, confirming that it is the loss of xRAR $\alpha$ protein that is responsible for the phenotype. To test whether RAR-mediated repression or activation was responsible for the rescue, we microinjected either a domi- 


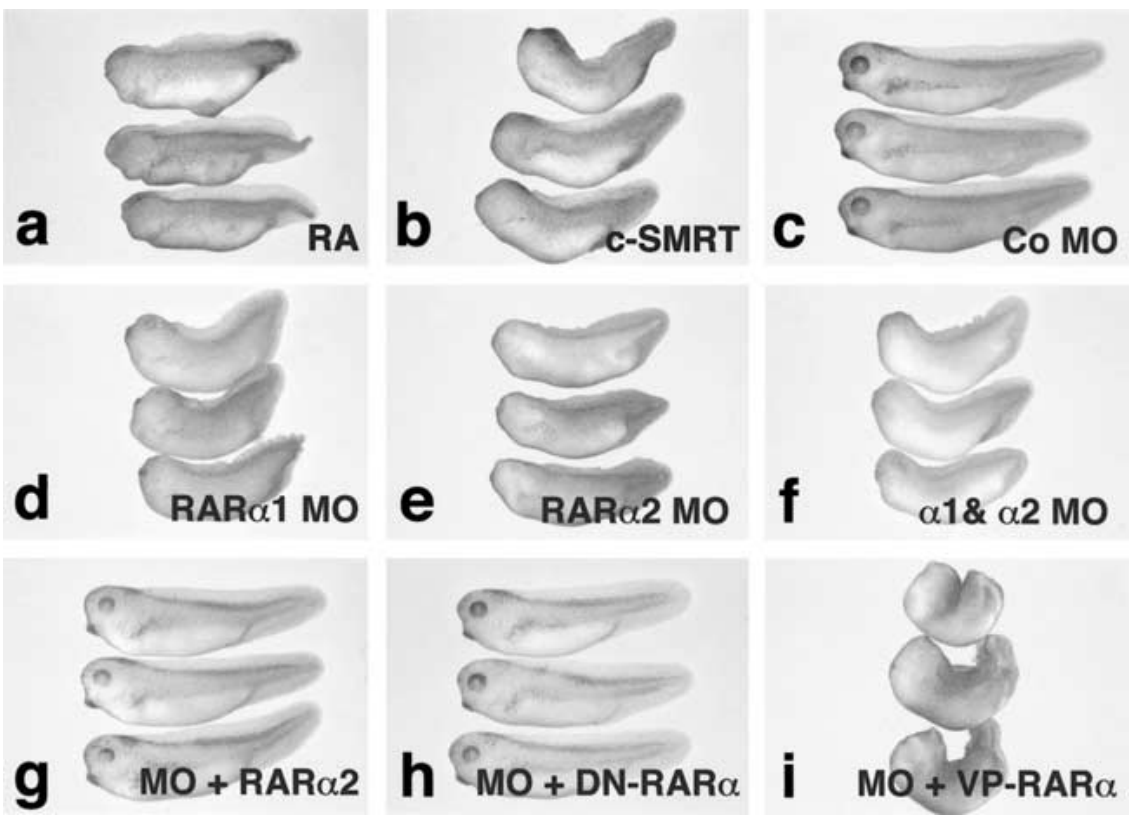

Figure 3. Effects of c-SMRT mRNA and morpholino oligonucleotide microinjection on Xenopus development. (a) Treatment with $10^{-6}$ RA causes anterior truncations; (b) c-SMRT overexpression causes anterior truncation similar to those elicited by RA treatment; $(c)$ embryos microinjected with $10 \mathrm{ng}$ of a control morpholino antisense oligonucleotide; (d) embryos microinjected with $10 \mathrm{ng}$ of a morpholino antisense oligonucleotide directed against $\mathrm{xRAR} \alpha 1$; $(e)$ embryos microinjected with $10 \mathrm{ng}$ of a morpholino antisense oligonucleotide directed against $x R A R \alpha 2 ;(f)$ embryo microinjected with 10 ng of a morpholino antisense oligonucleotide directed against both $\mathrm{xRAR} \alpha 1$ and $\mathrm{xRAR} \alpha 2$; $(g) 10 \mathrm{ng}$ of the $\mathrm{xRAR} \alpha 2$ morpholino was rescued by coinjection with 500 pg of $x R A R \alpha 2$ mRNA; (h) $10 \mathrm{ng}$ of the xRAR $\alpha 2$ morpholino was rescued by coinjection with $500 \mathrm{pg}$ of dominant-negative $\mathrm{xRAR} \alpha$ mRNA; (i) $10 \mathrm{ng}$ of the $\mathrm{xRAR} \alpha 2$ morpholino was not rescued by coinjection with 500 pg of constitutively active VP16-xRAR $\alpha$ mRNA. nant-negative (Fig. 3h) or constitutively active (Fig. 3i) variant of $x R A R \alpha 1$ (Blumberg et al. 1997). Only the dominant-negative receptor rescued the morpholino phenotype, confirming that repression by RAR was required for head formation. We conclude that reducing the degree of RAR-mediated target gene repression, either by blocking the ability of the receptor to repress transcription or by removing the receptor protein is essentially equivalent to RA treatment. This finding suggests that loss of RAR-mediated repression, rather than activation of RAR targets is primarily responsible for RA-induced defects in head formation.

\section{Derepression of RAR signaling reduces anterior marker expression}

We used microinjection of c-SMRT mRNA or morpholino antisense oligonucleotides followed by wholemount in situ hybridization with a panel of anterior neural marker genes to investigate the molecular basis of the anterior patterning defects elicited by derepressing RAR target genes. c-SMRT mRNA was microinjected into one dorsal blastomere of 8-cell embryos to allow precise comparison between the injected side of the embryo and the control uninjected contralateral side. Injected embryos exhibited reduced expression of Otx2 accompanied by a rostral shift in the posterior boundary of Otx2 expression (Fig. 4, cf. a and i). c-SMRT injection significantly reduced $\mathrm{xBF}-1$ and En2 transcript levels and shifted En2 rostrally (Fig. $4 b, j ; n=65$ ). At low doses (4 ng/embryo), the $x$ RAR $\alpha 2$ morpholino antisense oligonucleotide led to significant reduction of xOtx2, xBF-1, and En2 transcripts (data not shown). High doses (10 ng/ embryo) led to complete loss of xOtx2, xBF-1, and En2 transcripts (Fig. 4k,1; $n=30$ ). We infer that derepression of RAR target genes by either blocking receptor-mediated repression with a dominant-negative corepressor or by reducing the expression of $\mathrm{xRAR} \alpha 2$ causes reduction or loss of anterior marker gene expression.

\section{Increasing RAR-mediated repression enhances anterior marker expression}

Because derepression of RAR leads to the loss of heads (Fig. 3) and down-regulation of anterior markers (Fig. 4), we reasoned that increasing repression should have the opposite effect. Two classes of RA antagonists exist that differ in their ability to affect basal transcription. Neutral antagonists simply block the ability of RAR to bind RA, resulting in loss of activation (Klein et al. 1996). Inverse agonists also block RA binding but have the additional property of stabilizing the receptor-corepressor complex (Klein et al. 1996, 2000). Accordingly, inverse agonists lead to repression of basal transcription from promoters to which RARs bind. We used an RAR inverse agonist, AGN193109 (Johnson et al. 1995), to test the effects of increasing repression from RAR target genes. Treatment with AGN193109 reduces basal transcription from RAR target genes both in cell culture (Klein et al. 1996) and in microinjected embryos (Fig. 2). AGN193109-treated embryos were shorter and had larger heads and cement glands (Fig. 5b,c) than control embryos. AGN193109 treatment was able to overcome the effects of coadministered $10^{-6} \mathrm{M}$ RA in a dose-dependent manner (Fig. 5a). Half-maximal and maximal rescue is observed at a molar ratio of AGN193109:RA of $1: 1$ and 10:1(Fig. 5a), consistent with the results observed in transfection experiments (Klein et al. 1996). 
Koide et al.

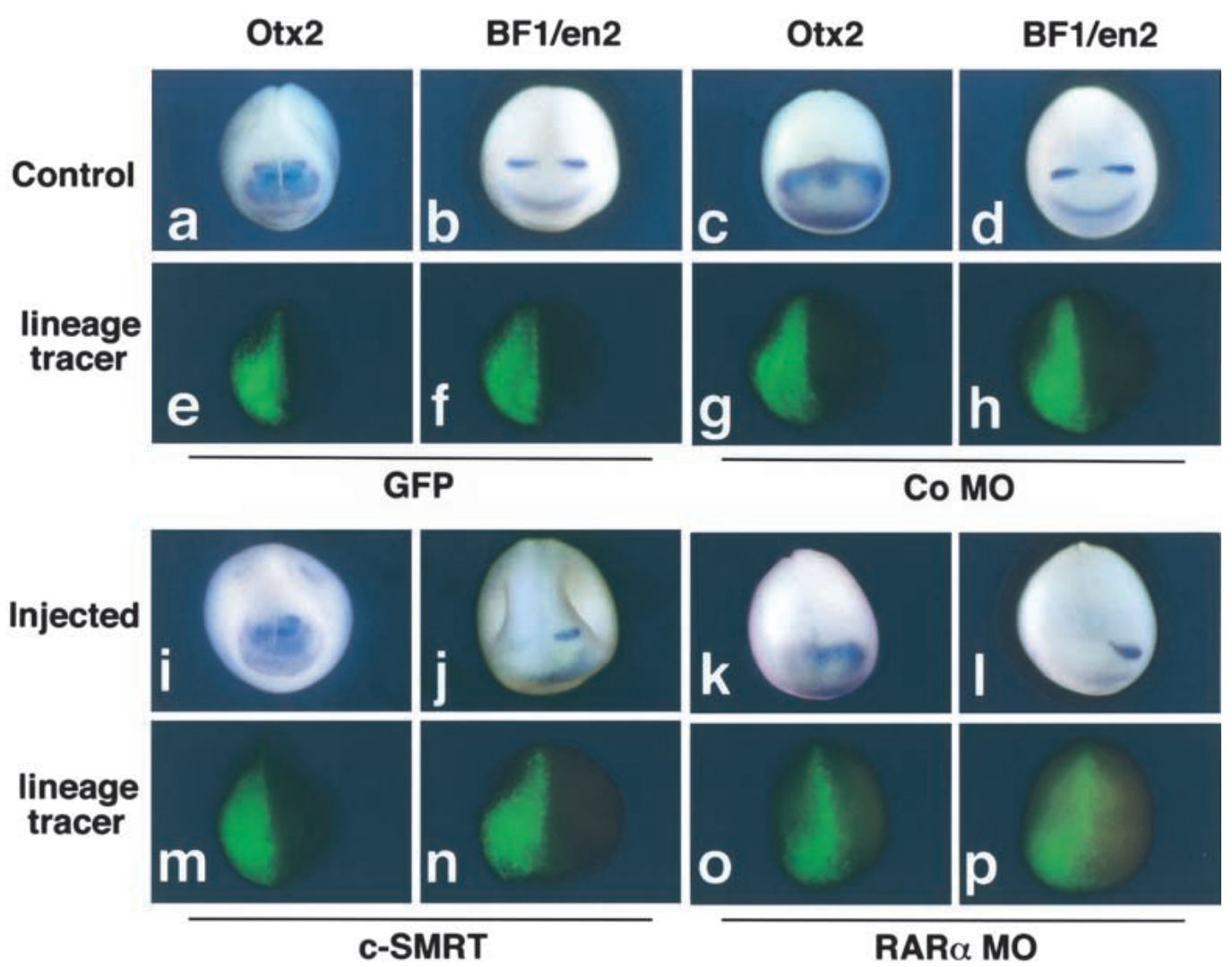

Figure 4. Changes in anterior neural marker expression elicited by removal of RAR-mediated repression. Whole-mount in situ hybridization analysis of Otx2 $(a, c, i, k)$ or BF1/Xen2 $(b, d, j, 1) \cdot(a, b, e, f)$ Control embryos injected with GFP mRNA. (c,d,g,h) Embryos injected with the control morpholino oligonucleotide. $(i, j)$ Embryos injected with 4 ng of C-SMRT and 200 pg of GFP mRNAs. (k,1) Embryos injected with $10 \mathrm{ng}$ of morpholino antisense oligonucleotide directed against xRAR $\alpha 2$ and $200 \mathrm{pg}$ of GFP mRNA. $(e-h, m-p)$ Fluorescence view of the embryos shown in $a-d$ and $i-1$, revealing the location of the GFP lineage tracer. Embryos were fixed at stage 16-18 and are shown with dorsal upward.

It is not possible to apply retinoids locally in the early embryo, therefore we used uniform treatment with AGN193109, or RA followed by RNase protection to quantitatively evaluate the expression of anterior marker mRNAs. XOtx2, XBF1, and XANF1 mRNAs were undetectable in RA-treated embryos (Fig. 5d). In contrast, treatment with AGN193109 led to a marked increase in the expression levels of all three anterior markers (Fig. 5d). This up-regulation of anterior neural markers by increased RAR-mediated repression provides strong support for our model.

\section{$R A R$ and head induction by cerberus}

The secreted molecule cerberus is thought to antagonize the ventralizing effects of BMPs, Wnts, and nodal genes to allow head formation (Bouwmeester et al. 1996; Piccolo et al. 1999|. However, this model has not been demonstrated conclusively by loss-of-function analysis (Simpson et al. 1999; Belo et al. 2000; Shawlot et al. 2000). When cerberus mRNA is microinjected into early Xenopus embryos, ectopic heads (as marked by eye and cement gland) are formed in $\sim 36 \%$ of the embryos
(Fig. 6). Because RAR-mediated repression is also required for head formation, we asked whether modulating RAR signaling affects the ability of cerberus to induce ectopic heads. Increasing RAR-mediated repression by microinjecting a dominant-negative $\mathrm{xRAR} \alpha 1$, or treating with AGN 193109, increased the number of ectopic heads to $71 \%$ and $88 \%$, respectively (Fig. 6). Conversely, coinjection of c-SMRT mRNA reduced the frequency of ectopic heads to $5 \%$ (Fig. 6). Therefore, we conclude that the degree of RAR-mediated repression strongly influences the ability of ectopic cerberus to induce head structures and that repression by RAR is absolutely required for head formation in Xenopus.

\section{Discussion}

Many unliganded nuclear receptors (RAR, VDR, TR) suppress the activity of promoters to which they bind /Glass and Rosenfeld 2000; Hu and Lazar 2000). This repression is mediated by interactions with corepressor proteins such as N-CoR and SMRT that recruit HDAC complexes to the promoter resulting in chromatin condensation (Glass and Rosenfeld 2000; Hu and Lazar 2000). Despite 

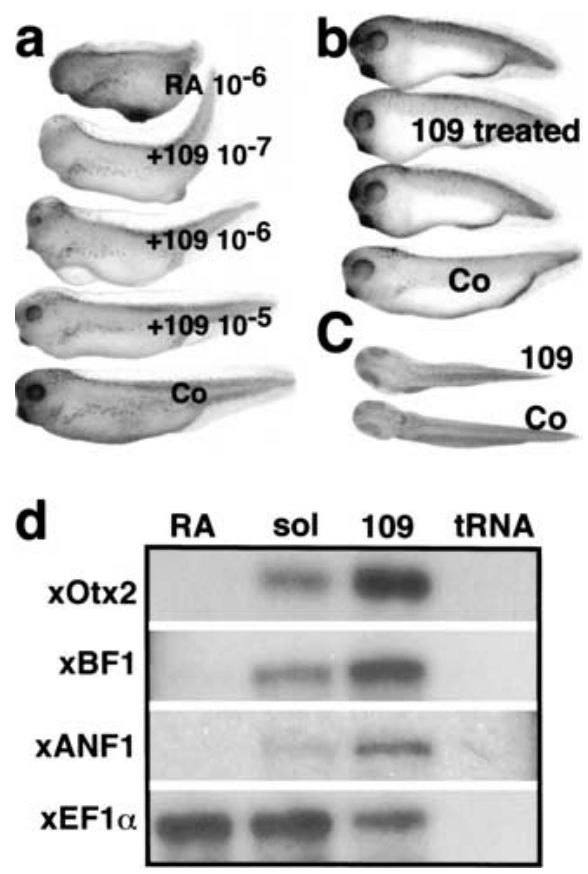

Figure 5. Effect of inverse agonist (AGN193109) on Xenopus development and expression of anterior markers. (a) The effects of AGN193109 were tested on $10^{-6}$ M RA-treated embryos. RA treated embryos (top), $10^{-6} \mathrm{M}$ RA $+10^{-7} \mathrm{M}$ AGN193109 (second), $10^{-6} \mathrm{M} \mathrm{RA}+10^{-6} \mathrm{M}$ AGN193109 (third), $10^{-6} \mathrm{M} \mathrm{RA}+10^{-5}$ M AGN193109 (fourth). (b) The effects of AGN193109 on normal Xenopus development. AGN193109 causes enlargement of head and short trunk (top three) compared with control embryo (bottom). (c) Dorsal view of embryo treated with AGN193109 (top) and control embryo (bottom). (d) Effects of RA and AGN193109 on anterior neural markers. Embryos were treated with RA (lane 1, RA), with AGN193109 (lane 3, 109), solvent control (lane 2, sol) and all were analyzed by RNase protection assay at the neural late stage (stage 20) for the expression of Xotx2, XBF1, and XANF1. Whereas RA suppressed the expression of all three markers (lane 1, RA), AGN193109 enhanced expression of the same markers (lane 3, 109).

intensive study by many laboratories, there has been little evidence until now for a required biological function associated with target gene suppression by unliganded nuclear receptors. It was shown recently that $\mathrm{N}$ CoR knockout mice exhibit increased levels of MAP2, suggesting that this putative RAR target gene was normally repressed in the developing CNS (Jepsen et al. 2000). Here, we have shown that active repression of RAR signaling is required for correct anterior specification as reflected by the expression of the anterior neural markers XOtx2, XBF-1, and Xen-2. Interference with RAR-mediated repression by microinjecting a dominantnegative corepressor or reducing $\mathrm{xRAR} \alpha$ protein with morpholino antisense oligonucleotides interfered with head formation (Fig. 3) and decreased the expression of anterior marker gene mRNAs (Fig. 4). In contrast, increasing RAR-mediated repression by use of the potent inverse agonist AGN193109 increased the mRNA levels of several anterior marker genes (Fig. 5). We conclude that removing RAR-mediated repression posteriorizes the neural plate, whereas increasing RAR-mediated repression is able to anteriorize the neural plate. Thus, it is repression mediated by the unliganded receptor/corepressor complex, rather than the activity of liganded RARs, that is required for the correct expression levels and spatial restriction of anterior markers during head formation in Xenopus embryos. This result establishes a novel requirement for active repression of RAR signaling during early development and shows an important function for target gene repression by unliganded nuclear receptors. It also explains the apparently paradoxical expression of RARs in regions of the embryo that require the absence of retinoid signaling for correct patterning.

Another line of evidence suggesting that absence of retinoid signaling is required for anterior development comes from the study of XCYP26, an enzyme that is believed to mediate RA clearance (White et al. 1996). In gastrula stage Xenopus embryos, XCYP26 is expressed in the prospective neuroectoderm and in the mesoderm that will later form prechordal plate (Hollemann et al. 1998; de Roos et al. 1999). Ectopic expression of XCYP26
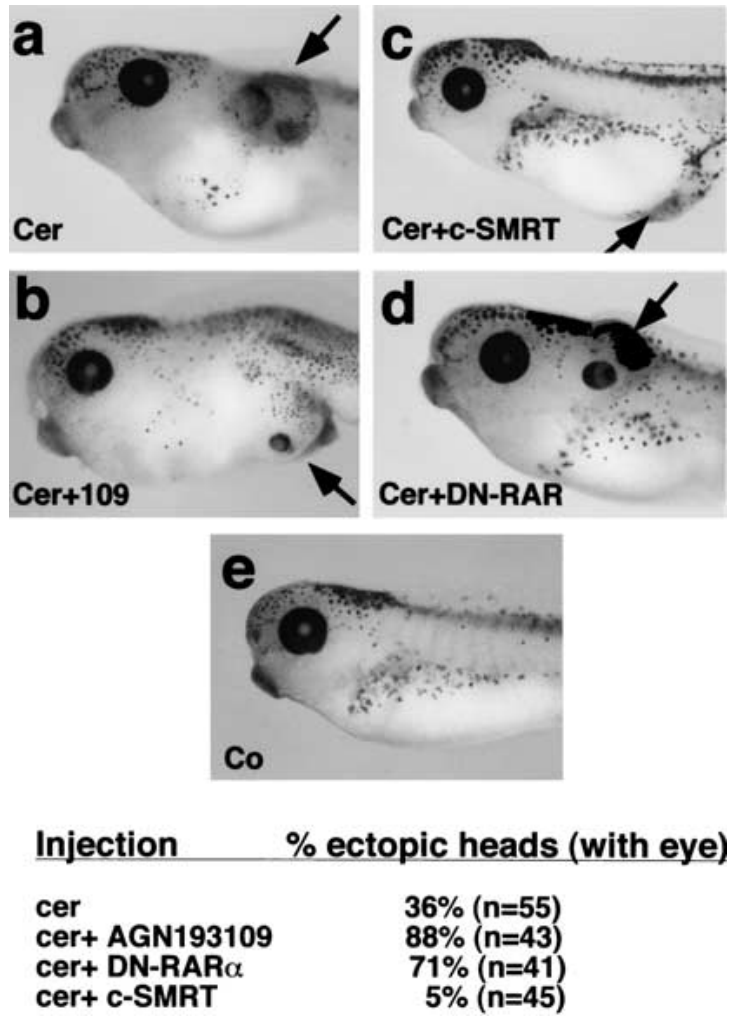

Figure 6. Modulating RAR signaling affects head induction by cerberus. (a) An ectopic head is induced in an embryo injected with 100 pg of cerberus mRNA in the D4 blastomere at 32-cell stage. (b) Ectopic head formation by cerberus is enhanced when embryos are treated with AGN193109 or (d) 1 ng of DN-RAR mRNA is coinjected with $100 \mathrm{pg}$ of cerberus mRNA into the D4 blastomere. (c) The formation of ectopic heads by cerberus is inhibited when $1 \mathrm{ng}$ of c-SMRT mRNA is coinjected with 100 pg of cerberus mRNA into the D4 blastomere. (e) Control embryo. 
anteriorizes the developing hindbrain causing a caudal shift of Krox-20 while also causing an expansion of the forebrain, as marked by Otx-2 (Hollemann et al. 1998). These data confirm our previous experiments using the strong dominant-negative RAR, $x R A R \alpha 1^{405^{*}}$ (Blumberg et al. 1997) and suggest that the failure of other laboratories to reproduce this phenotype (Kolm et al. 1997; van der Wees et al. 1998) results from the different reagents used in their studies. A possible requirement for RARmediated repression in the head is further supported by two recent reports describing mice lacking CYP26 (AbuAbed et al. 2001; Sakai et al. 2001). Disruption of CYP26 caused exencephaly that resembled the teratogenic effects of RA. These results suggest that that the absence of retinoid signaling is required for head formation. We further conclude from the results presented here that it is not the absence of retinoid signaling per se that is required, but rather active repression by unliganded RARs. Such repression might be aided by the presence of a hypothetical endogenous inverse agonist with corepressor-recruiting properties expressed in the anterior of the developing embryo.

A further novel finding is that we show here for the first time that ablation of a single RAR isoform, $\mathrm{xRAR} \alpha 2$, is sufficient to generate an unambiguous embryonic phenotype. This stands in stark contrast to the mouse knockout experiments in which multiple receptor subtypes (e.g., RAR $\alpha^{-} / \beta^{-}$) must be removed before phenotypes are observable (Mark et al. 1999). The reason for this discrepancy between systems is unclear at present. There is evidence that indicates other RARs are upregulated in response to the loss of particular RARs in mice, suggesting a functional redundancy (Mark et al. 1999|. One possibility is that Xenopus lacks the redundant mechanism present in mice allowing the specific functions of individual RAR subtypes and isoforms to be revealed. Another possibility is that because RARs are expressed maternally (Fig. 1; Blumberg et al. 1992; Sharpe 1992), RAR-mediated repression is required at very early stages of development. In this scenario, it might not be possible to compensate for the loss of $\mathrm{xRAR} \alpha 2$ by up-regulating another RAR, as zygotic transcription does not begin until the midblastula stage (Newport and Kirschner 1982a,b). The early window of embryonic sensitivity to RA and the spatial localization of xRAR transcripts suggests that RAR-mediated repression is required very early in development.

Induction of vertebrate head structures is thought to involve the simultaneous inhibition of BMP, Wnt, and nodal signaling (Sasai and De Robertis 1997; Weinstein and Hemmati-Brivanlou 1999). Such inhibition is mediated by secreted antagonists such as cerberus (Piccolo et al. 1999), chordin (Sasai et al. 1994; Sasai and De Robertis 1997; Bachiller et al. 2000), follistatin (Hemmati-Brivanlou et al. 1994; Fainsod et al. 1997), dickkopf (Glinka et al. 1998), and noggin (Knecht and Harland 1997). The requirement for RAR-mediated repression shown here suggests a simultaneous requirement for the repression of retinoid and certain growth-factor signaling pathways in head development.
We showed previously that active signaling through RARs is required for the expression of posterior neural markers (Blumberg et al. 1997). In addition to retinoids, several other factors have been implicated in neural posteriorization. These include growth factors such as cripto (Ciccodicola et al. 1989), derriere (Sun et al. 1999), FGFs (Pownall et al. 1996, 1998; Isaacs et al. 1998), and members of the Wnt family (McGrew et al. 1997, 1999). Taken together, all of these data suggest that repression of both retinoid and growth-factor signaling is required for head formation, whereas activation of both types of signals is required for neural posteriorization. We infer that there are multiple points of interaction between retinoid and growth-factor signaling and that further investigation of the molecular nature of these interactions will be necessary to fully understand patterning along the $\mathrm{A} / \mathrm{P}$ axis.

\section{Materials and methods}

Embryo culture and retinoid treatment

Xenopus embryos were obtained by in vitro fertilization and staged according to Nieuwkoop and Faber and cultured as described (Blumberg et al. 1996, 1997). All-trans-retinoic acid (RA) was purchased from Sigma. Inverse agonist AGN 193109 was synthesized at Allergan (Johnson et al. 1995). Retinoid treatments were performed from stage 8 to stage $18-20$ at $16-19^{\circ} \mathrm{C}$.

\section{Microinjection and whole-mount in situ hybridization}

mRNAs were synthesized from SfiI-linearized CMX-c-SMRT (Chen et al. 1996), CMX-GFP (Ogawa et al. 1995), and CMXGAL-xRAR $\alpha$ (Blumberg et al. 1996) by use of the bacteriophage T7 RNA polymerase-based mMessage mMachine kit (Ambion). A total of $4 \mathrm{ng}$ of c-SMRT mRNA, $0.4 \mathrm{ng}$ of GAL-xRAR $\alpha 2$ and/or 200 pg of GFP mRNAs were injected bilaterally or unilaterally into dorsal blastomeres of 8-cell stage embryos. A total of 4 or $10 \mathrm{ng}$ of $\mathrm{xRAR} \alpha 1$ GCTCCAAACGCACTTCTACTC CCTC, xRAR $\alpha 2$ (ATCCAAAGGAAGGTGAGTGTGTGTG), or control (CCTCTTACCTCAGTTACAATTTATA) morpholino antisense oligonucleotides were injected bilaterally or unilaterally at the 2-cell stage.

Whole-mount in situ hybridization was performed essentially as described (Blumberg et al. 1997). Otx2 and En-2 were as described previously (Blumberg et al. 1997). The BF1 probe was prepared by PCR amplification of the entire protein coding regions of the respective cDNA, adding a T7 RNA polymerase promoter at the $3^{\prime}$ end and an SP6 RNA polymerase promoter at the $5^{\prime}$ end. Digoxygenin-labeled sense and antisense probes were prepared as described (Blumberg et al. 1997).

\section{Luciferase assay}

The luciferase-based reporter construct tk(MH100 $)_{4}$-luc has been described (Blumberg et al. 1996). A total of $100 \mathrm{ng}$ of reporter DNA was mixed with GFP mRNA and effector (GAL$x R A R \alpha$, and/or c-SMRT) mRNAs in sterile $\mathrm{H}_{2} \mathrm{O}$, then microinjected into both dorsal blastomeres of 8-cell embryos. Embryos were collected at stage 16 and evaluated by fluorescent microscopy to identify embryos expressing GFP in the prospective head. Groups of five such embryos were homogenized in $50 \mu \mathrm{L}$ of lysis buffer. After a brief centrifugation, $20 \mu \mathrm{L}$ of the extracts were used for luciferase assays (Blumberg et al. 1996). 


\section{RNase protection and $R T-P C R$ assay}

Embryos were collected at stage 20-23. RNA was isolated and assayed by RNase protection with the RPAIII kit (Ambion). The Ef- $1 \alpha$ probe was as described previously (Blumberg et al. 1992). To make antisense probes for XOtx2, XBF1, and XANF1, PCR was performed by adding bacteriophage T7 (antisense) or SP6 (sense) promoter sequences. After amplification, PCR products were added directly to the transcription reaction and $\left[{ }^{32} \mathrm{P}\right] \mathrm{UTP}$ sense or antisense probes produced by use of MaxiScript kits (Ambion).

RNA was isolated from embryonic tissues and RT-PCR was performed as described (Niehrs et al. 1994). For PCR reactions, the following primer sets were used: xRARa1, F 5'-GGACTC GCAAAGATAGAGCG-3'， R 5'AGCATAATGGGGTACGTG GA-3'; xRARa2, F 5'-CTGGGAATATGGACATTGGG-3'， R 5'-GCTCCCCAAACCCTTTAGAC-3'; xSMRT, F 5'-AAAC CCATTTCACСТCСТCC-3', R 5'-CAGGCTTCCATTAGC TGGTC-3'; xN-CoR, F 5'-AGAATTTCACCCAGTGTCCG-3', R 5'-TTGGCAAACCTTGTTCCTTC-3'.

\section{Acknowledgments}

This paper is dedicated to the memory of Professor Kazuhiko Umesono, a dear friend, colleague, and mentor who died before his time. Supported by a grant from the National Science Foundation (IBN-9904764) and National Institutes of Health (GM60572 ) to B.B. We thank R. Kaigh, I. Blitz, and members of the Blumberg laboratory for comments on the manuscript, T. Schilling for the control morpholino oligonucleotide, and K. Cho for sharing his frog facilities. T.K. wishes to thank M. Takeichi and C. Hashimoto for encouragement of this work.

The publication costs of this article were defrayed in part by payment of page charges. This article must therefore be hereby marked "advertisement" in accordance with 18 USC section 1734 solely to indicate this fact.

\section{References}

Abu-Abed, S., Dolle, P., Metzger, D., Beckett, B., Chambon, P., and Petkovich, M. 2001. The retinoic acid-metabolizing enzyme, CYP26A1, is essential for normal hindbrain patterning, vertebral identity, and development of posterior structures. Genes \& Dev. 15: 226-240.

Achkar, C., Derguini, F., Blumberg, B., Langston, A., Levin, A.A., Speck, J., Evans, R.M., Bolado, J.J., Buck, J., and Gudas, L.J. 1996. 4-oxo-retinol, a new natural ligand and transactivator of the retinoic acid receptors. Proc. Natl. Acad. Sci. 93: 4879-4884.

Bachiller, D., Klingensmith, J., Kemp, C., Belo, J.A., Anderson, R.M., May, S.R., McMahon, J.A., McMahon, A.P., Harland, R.M., Rossant, J., et al. 2000. The organizer factors Chordin and Noggin are required for mouse forebrain development. Nature 403: 658-661.

Belo, J.A., Bachiller, D., Agius, E., Kemp, C., Borges, A.C., Marques, S.,. Piccolo, S., and De Robertis, E.M. 2000. Cerberus-like is a secreted BMP and nodal antagonist not essential for mouse development. Genesis 26: 265-270.

Blumberg, B. 1997. An essential role for retinoid signaling in anteroposterior neural specification and neuronal differentiation. Semin. Cell Dev. Biol. 8: 417-428.

Blumberg, B., Mangelsdorf, D.J., Dyck, J., Bittner, D.A., Evans, R.M., and De Robertis, E.M. 1992. Multiple retinoid-responsive receptors in a single cell: Families of RXRs and RARs in the Xenopus egg. Proc. Nat1. Acad. Sci. 89: 2321-2325.
Blumberg, B., Bolado, Jr., J., Derguini, F., Craig, A.G., Moreno, T.A., Charkravarti, D., Heyman, R.A., Buck, J., and Evans, R.M. 1996. Novel RAR ligands in Xenopus embryos. Proc. Natl. Acad. Sci. 93: 4873-4878.

Blumberg, B., Bolado, J., Moreno, T.A., Kintner, C., Evans, R.M., and Papalopulu, N. 1997. An essential role for retinoid signaling in anteroposterior neural patterning. Development 124: 373-379.

Bouwmeester, T., Kim, S., Sasai, Y., Lu, B., and De Robertis, E.M. 1996. Cerberus is a head-inducing secreted factor expressed in the anterior endoderm of Spemann's organizer. Nature 382: 595-601.

Chen, J.D., Umesono, K., and Evans, R.M. 1996. SMRT isoforms mediate repression and anti-repression of nuclear receptor heterodimers. Proc. Natl. Acad. Sci. 93: 7567-7571.

Chen, Y., Pollet, N., Niehrs, C., and Pieler, T. 2001. Increased XRALDH2 activity has a posteriorizing effect on the central nervous system of Xenopus embryos. Mech. Dev. 101:91103.

Ciccodicola, A., Dono, R., Obici, S., Simeone, A., Zollo, M., and Persico, M.G. 1989. Molecular characterization of a gene of the 'EGF family' expressed in undifferentiated human NTERA2 teratocarcinoma cells. EMBO J. 8: 1987-1991.

de Roos, K., Sonneveld, E., Compaan, B., ten Berge, D., Durston, A.J., and van der Saag, P.T. 1999. Expression of retinoic acid 4-hydroxylase (CYP26) during mouse and Xenopus laevis embryogenesis. Mech. Dev. 82: 205-211.

de Urquiza, A.M., Liu, S., Sjoberg, M., Zetterstrom, R.H., Griffiths, W., Sjovall, J., and Perlmann, T. 2000. Docosahexaenoic acid, a ligand for the retinoid $\mathrm{X}$ receptor in mouse brain. Science 290: 2140-2144.

Durston, A.J., Timmermans, J.P., Hage, W.J., Hendriks, H.F., de Vries, N.J., Heideveld, M., and Nieuwkoop, P.D. 1989. Retinoic acid causes an anteroposterior transformation in the developing central nervous system. Nature 340: 140-144.

Ekker, S.C. 2000. Morphants: A new systematic vertebrate functional genomics approach. Yeast 17: 302-306.

Ellinger-Ziegelbauer, H. and Dreyer, C. 1991. A retinoic acid receptor expressed in the early development of Xenopus laevis. Genes \& Dev. 5: 94-104.

- 1993. The pattern of retinoic acid receptor g (RARg) expression in normal development of Xenopus laevis and after manipulation of the main body axis. Mech. Dev. 41: 3346.

Fainsod, A., Deissler, K., Yelin, R., Marom, K., Epstein, M., Pillemer, G., Steinbeisser, H., and Blum, M. 1997. The dorsalizing and neural inducing gene follistatin is an antagonist of BMP-4. Mech. Dev. 63: 39-50.

Glass, C.K. and Rosenfeld, M.G. 2000. The coregulator exchange in transcriptional functions of nuclear receptors. Genes \& Dev. 14: 121-141.

Glinka, A., Wu, W., Delius, H., Monaghan, A.P., Blumenstock, C., and Niehrs, C. 1998. Dickkopf-1 is a member of a new family of secreted proteins and functions in head induction. Nature 391: 357-362.

Heasman, J., Kofron, M., and Wylie, C. 2000. Beta-catenin signaling activity dissected in the early Xenopus embryo: A novel antisense approach. Dev. Biol. 222: 124-134.

Hemmati-Brivanlou, A., Kelly, O.G., and Melton, D.A. 1994. Follistatin, an antagonist of activin, is expressed in the Spemann organizer and displays direct neuralizing activity. Cell 77: 283-295.

Hollemann, T., Chen, Y., Grunz, H., and Pieler, T. 1998. Regionalized metabolic activity establishes boundaries of retinoic acid signalling. EMBO J. 17: 7361-7372.

Horlein, A.J., Naar, A.M., Heinzel, T., Torchia, J., Gloss, B., 
Kurokawa, R., Ryan, A., Kamei, Y., Soderstrom, M., Glass, C.K., and Rosenfeld, M.G. 1995. Ligand-independent repression by the thyroid hormone receptor mediated by a nuclear receptor co-repressor. Nature 377: 397-404.

Hu, I. and Lazar, M.A. 2000. Transcriptional repression by nuclear hormone receptors. Trends Endocrinol. Metab. 11: 6-10.

Isaacs, H.V., Pownall, M.E., and Slack, J.M. 1998. Regulation of Hox gene expression and posterior development by the Xenopus caudal homologue Xcad3. EMBO J. 17: 3413-3427.

Jepsen, K., Hermanson, O., Onami, T.M., Gleiberman, A.S., Lunyak, V., McEvilly, R.J., Kurokawa, R., Kumar, V., Liu, F., Seto, E., et al. 2000. Combinatorial roles of the nuclear receptor corepressor in transcription and development. Cell 102: 753-763.

Johnson, A.T., Klein, E.S., Gillett, S.J., Wang, L., Song, T.K., Pino, M.E., and Chandraratna, R.A. 1995. Synthesis and characterization of a highly potent and effective antagonist of retinoic acid receptors. J. Med. Chem. 38: 4764-4767.

Kitareewan, S., Burka, L.T., Tomer, K.B., Parker, C.E., Deterding, L.J., Stevens, R.D., Forman, B.M., Mais, D.E., Heyman, R.A., McMorris, T., et al. 1996. Phytol metabolites are circulating dietary factors that activate the nuclear receptor RXR. Mol. Biol. Cell 7: 1153-1166.

Klein, E.S., Pino, N.E., Johnson, A.T., Davies, P.J., Nagpal, S., Thacher, S.M., Krasinski, G., and Chandraratna, R.A.S. 1996. Identification and functional separation of retinoic acid receptor neutral antagonists and inverse agonists. $I$. Biol. Chem. 271: 22691-22696.

Klein, E.S., Wang, J.W., Khalifa, B., Gavigan, S.A., and Chandraratna, R.A. 2000. Recruitment of nuclear receptor corepressor and coactivator to the retinoic acid receptor by retinoid ligands. Influence of DNA-heterodimer interactions. $J$. Biol. Chem. 275: 19401-19408.

Knecht, A.K. and Harland, R.M. 1997. Mechanisms of dorsalventral patterning in noggin-induced neural tissue. Development 124: 2477-2488.

Kolm, P.J., Apekin, V., and Sive, H. 1997. Xenopus hindbrain patterning requires retinoid signaling. Dev. Biol. 192: 1-16.

Maden, M. 1999. Heads or tails? Retinoic acid will decide. BioEssays 21: 809-812.

Mangelsdorf, D.J. and Evans, R.M. 1995. The RXR heterodimers and orphan receptors. Cell 83: 841-850.

Mannervik, M., Nibu, Y., Zhang, H., and Levine, M. 1999. Transcriptional coregulators in development. Science 284: 606609.

Mark, M., Ghyselinck, N.B., Wendling, O., Dupe, V., Mascrez, B., Kastner, P., and Chambon, P. 1999. A genetic dissection of the retinoid signalling pathway in the mouse. Proc. Nutr. Soc. 58: 609-613.

McGrew, L.L., Hoppler, S., and Moon, R.T. 1997. Wnt and FGF pathways cooperatively pattern anteroposterior neural ectoderm in Xenopus. Mech. Dev. 69: 105-114.

McGrew, L.L., Takemaru, K., Bates, R., and Moon, R.T. 1999. Direct regulation of the Xenopus engrailed-2 promoter by the Wnt signaling pathway, and a molecular screen for Wntresponsive genes, confirm a role for Wnt signaling during neural patterning in Xenopus. Mech. Dev. 87: 21-32.

Minucci, S. and Pelicci, P.G. 1999. Retinoid receptors in health and disease: Co-regulators and the chromatin connection. Semin. Cell. Dev. Biol. 10: 215-225.

Newport, J. and Kirschner, M. 1982a. A major developmental transition in early Xenopus embryos: II. Control of the onset of transcription. Cell 30: 687-696.

. 1982b. A major developmental transition in early Xenopus embryos: I. Characterization and timing of cellular changes at the midblastula stage. Cell 30: 675-686.

Niederreither, K., Subbarayan, V., Dolle, P., and Chambon, P. 1999. Embryonic retinoic acid synthesis is essential for early mouse post-implantation development. Nat. Genet. 21: 444-448.

Niehrs, C., Steinbeisser, H., and De Robertis, E.M. 1994. Mesodermal patterning by a gradient of the vertebrate homeobox gene goosecoid. Science 263: 817-820.

Ogawa, H., Inouye, S., Tsuji, F.I., Yasuda, K., and Umesono, K. 1995. Localization, trafficking, and temperature-dependence of the Aequorea green fluorescent protein in cultured vertebrate cells. Proc. Nat1. Acad. Sci. 92: 11899-11903.

Pfeffer, P.L. and De Robertis, E.M. 1994. Regional specificity of RAR gamma isoforms in Xenopus development. Mech. Dev. 45: $147-153$.

Piccolo, S., Agius, E., Leyns, L., Bhattacharyya, S., Grunz, H., Bouwmeester, T., and De Robertis, E.M. 1999. The head inducer Cerberus is a multifunctional antagonist of Nodal, BMP and Wnt signals. Nature 397: 707-710.

Pijnappel, W.W., Hendriks, H.F., Folkers, G.E., van den Brink, C.E., Dekker, E.J., Edelenbosch, C., van der Saag, P.T., and Durston, A.J. 1993. The retinoic ligand 4-oxy-retinoic acid is a highly active modulator of positional specification. Nature 366: 340-344.

Pijnappel, W.W.M., Folkers, G.E., de Jonge, W.J., Verdegem, P.J.E., de Laat, S.W., Lugtenburg, J., Hendriks, H.F.J., van der Saag, P.T., and Durston, A.J. 1998. Metabolism to a response pathway selective retinoid ligand during axial pattern formation. Proc. Natl. Acad. Sci. 95: 15424-15429.

Pownall, M.E., Tucker, A.S., Slack, J.M.W., and Isaacs, H.V. 1996. eFGF, Xcad3, and Hox genes form a molecular pathway that establishes the anteroposterior axis in Xenopus. Development 122: 3881-3892.

Pownall, M.E., Isaacs, H.V., and Slack, J.M. 1998. Two phases of Hox gene regulation during early Xenopus development. Curr. Biol. 8: 673-676.

Privalsky, M.L. 2001. Regulation of SMRT and N-CoR corepressor function. Curr. Top. Microbiol. Immunol. 254: 117-136.

Rossant, J., Zirngibl, R., Cado, D., Shago, M., and Giguere, V. 1991. Expression of a retinoic acid response elementhsplacZ transgene defines specific domains of transcriptional activity during mouse embryogenesis. Genes \& Dev. 5: 1333-1344.

Sakai, Y., Meno, C., Fujii, H., Nishino, J., Shiratori, H., Saijoh, Y., Rossant, J., and Hamada, H. 2001. The retinoic acid-inactivating enzyme CYP26 is essential for establishing an uneven distribution of retinoic acid along the anterio- posterior axis within the mouse embryo. Genes \& Dev. 15: 213-225.

Sasai, Y. and De Robertis, E.M. 1997. Ectodermal patterning in vertebrate embryos. Dev. Biol. 182: 5-20.

Sasai, Y., Lu, B., Steinbeisser, H., Geissert, D., Gont, L.K., and De Robertis, E.M. 1994. Xenopus chordin: A novel dorsalizing factor activated by organizer-specific homeobox genes. Cell 79: 779-790.

Sharpe, C. and Goldstone, K. 2000. The control of Xenopus embryonic primary neurogenesis is mediated by retinoid signalling in the neurectoderm. Mech. Dev. 91: 69-80.

Sharpe, C.R. 1992. Two isoforms of retinoic acid receptor alpha expressed during Xenopus development respond to retinoic acid. Mech. Dev. 39: 81-93.

Sharpe, C.R. and Goldstone, K. 1997. Retinoid receptors promote primary neurogenesis in Xenopus. Development 124: 515-523.

Shawlot, W., Min Deng, J., Wakamiya, M., and Behringer, R.R. 2000. The cerberus-related gene, Cerrl, is not essential for mouse head formation. Genesis 26: 253-258. 
Simpson, E.H., Johnson, D.K., Hunsicker, P., Suffolk, R., Jordan, S.A., and Jackson, I.J. 1999. The mouse Cer1 (Cerberus related or homologue) gene is not required for anterior pattern formation. Dev. Biol. 213: 202-206.

Summerton, J. 1999. Morpholino antisense oligomers: The case for an RNase H-independent structural type. Biochim. Biophys. Acta 1489: 141-158.

Sun, B.I., Bush, S.M., Collins-Racie, L.A., LaVallie, E.R., DiBlasio-Smith, E.A., Wolfman, N.M., McCoy, J.M., and Sive, H.L. 1999. Derriere: A TGF-beta family member required for posterior development in Xenopus. Development 126: $1467-$ 1482.

Swindell, E.C., Thaller, C., Sockanathan, S., Petkovich, M., Jessell, T.M., and Eichele, G. 1999. Complementary domains of retinoic acid production and degradation in the early chick embryo. Dev. Biol. 216: 282-296.

van der Wees, J., Schilthuis, J.G., Koster, C.H., Diesveld-Schipper, H., Folkers, G.E., van der Saag, P.T., Dawson, M.I., Shudo, K., van der Burg, B., and Durston, A.J. 1998. Inhibition of retinoic acid receptor-mediated signalling alters positional identity in the developing hindbrain. Development 125: 545-556.

Weinstein, D.C. and Hemmati-Brivanlou, A. 1999. Neural induction. Annu. Rev. Cell. Dev. Biol. 15: 411-433.

White, J.A., Guo, Y.D., Baetz, K., Beckett-Jones, B., Bonasoro, J., Hsu, K.E., Dilworth, F.J., Jones, G., and Petkovich, M. 1996. Identification of the retinoic acid-inducible all-trans-retinoic acid 4-hydroxylase. J. Biol. Chem. 271: 29922-29927.

$\mathrm{Xu}$, L., Glass, C.K., and Rosenfeld, M.G. 1999. Coactivator and corepressor complexes in nuclear receptor function. Curr. Opin. Genet. Dev. 9: 140-147. 


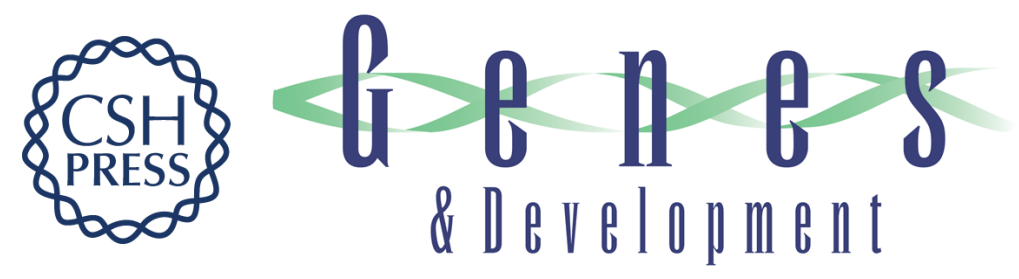

\section{Active repression of RAR signaling is required for head formation}

Tetsuya Koide, Michael Downes, Roshantha A.S. Chandraratna, et al.

Genes Dev. 2001, 15:

Access the most recent version at doi:10.1101/gad.908801

References This article cites 68 articles, 25 of which can be accessed free at: http://genesdev.cshlp.org/content/15/16/2111.full.html\#ref-list-1

License

Email Alerting Receive free email alerts when new articles cite this article - sign up in the box at the top Service right corner of the article or click here.

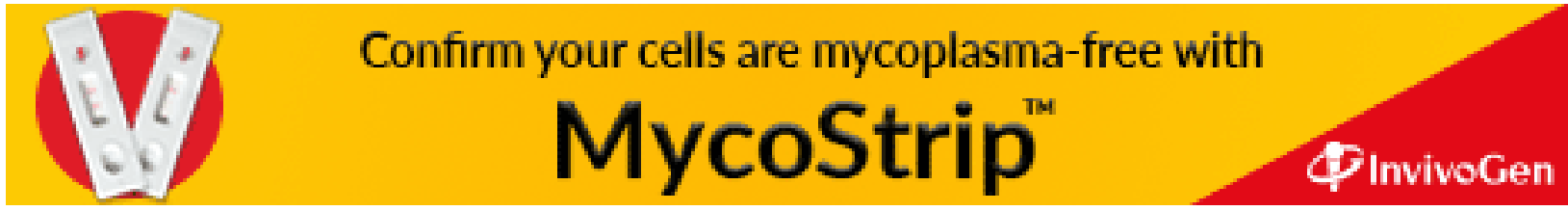

